\title{
Miliarial type pseudolymphoma mimicking as granulomatous rosacea
}

\author{
Gharaei Nejad Kaveh1, Rafiei Rana', Azimi Seyyede Zeinab', Rafiee Behnam² \\ ${ }^{1}$ Skin Research Center, Guilan University of Medical Sciences, Razi Hospital, Sardare Jangal Street, Rasht, Iran, ${ }^{2}$ Research \\ intern. University of Texas, MD Anderson Cancer Center 1515 Holcombe blvd.B4.4512, Houston, TX, 77030, USA
}

Corresponding author: Rana Rafiei, MD, E-mail: rafieirana@yahoo.com

\begin{abstract}
Miliarial type lymphocytoma cutis is a rare type of psuedolymphoma which is described by numerous semi-translucent papules on the sun exposed regions. Herein, we present a 25-year-old woman with numerous permanent translucent tiny papules on the face. Microscopic examination revealed dense infiltration of lymphocytes in the reticular dermis with lymphoid follicle formation and significant B-cell lymphocytes in immunohistochemistry study. She was diagnosed as miliarial type pseudolymphoma and treated with topical momethasone furoate ointment and oral hydroxychloroquine with a good response.
\end{abstract}

Key words: Miliarial pseudolymphoma; Rosacea; Cutaneous lymphoid hyperplasia; lymphocytoma cutis

\section{INTRODUCTION}

Cutaneous lymphoid hyperplasia (CLH) is a subtype of cutaneous pseudolymphoma which is also named lymphocytoma cutis and affects females more than males. Histopatholgically, CLH is characterized by a dense mixed $\mathrm{B}$ and $\mathrm{T}$ cell lymphocytic infiltration in reticular dermis with a nodular or diffuse pattern [1].

Although due to predominance of B-cell lymphocyte, CLH could be categorized as B-cell pseudolymphoma. Lymphoid follicle with germinal center is a characteristic feature which consists of B-cell lymphocytes and macrophages surrounded by T-cell lymphocytes [2].

CLH is usually manifested by a solitary nodule on the face and limbs but rarely diffuse shiny papular eruptions have been reported [3-6]. Different etiologic factors have been proposed but in most cases it is idiopathic. Arthropod bite, infections such as borreliosis, Infestations such as scabies, trauma, vaccination, tattoo, gold, nickel and drugs all have been incriminated $[1,2]$.

\section{CASE REPORT}

We report a 25-year-old woman who developed numerous persistent firm translucent asymptomatic erythematous micropapules measuring $1-3 \mathrm{~mm}$ on her face which were persistent, started 6 years ago with no improvement and gradually were increased (Fig. la). She had mild pruritus or burning when the lesions were aggravated by sun exposure.

She was a midwife and also worked as a part of immunization team in a primary health care center. In physical examination there were micropapules mostly on the forehead and cheeks without any scale, scar, comedone, pustule or telangiectasia. Papules on the forehead were seemed translucent. Diascopy was made and the result has been shown in Fig. 1b. Also there were discrete erythematous papules on dorsal aspect of her hands. She mentioned these lesions were transient and manifested in summer time (Fig. lc).

She was doing well and in physical examinations there were no lymphadenopathy and organomegaly. She had history of hand dermatitis, nickel allergy and allergic 
blepharo-conjunctivitis but there were no history of insect bite, tick bite, sun burn and gold allergy. In family history his father had vitiligo.

She was initially diagnosed as a case of eruptive multiple hidrocystoma without skin biopsy due to translucency of the lesions and she was treated with aluminium chloride $15 \%$ solution with no improvement. So skin biopsy was made from forehead region. Differential diagnoses were rosacea, sarcoidosis, colloid milium, acne agminata, apocrine hidrocystoma, discoid lupus erythematosus, papular pseudolymphoma. First biopsy revealed unremarkable epidermis with perifollicular collections of lymphocytes and histiocytes in superficial dermis and rare demodex mites in follicular infundibulum. Lupus band test was negative. Mucin staining was negative. All of these findings were compatible with granulomatous rosacea. So permethrin cream 5\% and isotretinoin capsules $20 \mathrm{mg}$ daily were administered by another dermatologist for a three-month period without any improvement. Nine months later she was referred to our clinic due to atypical presentation, unresponsiveness to treatment and exacerbation of the lesions so re-biopsy was recommended. Two specimens were taken from her cheek bilaterally. This time, histopathologic changes in both specimens were as follows: a flattened epidermis with an underlying Grenz zone (thin uninvolved region in upper dermis), dense lymphoid follicle aggregations with ill-defined germinal center in mid and deep dermis without atypical lymphocytes. (Fig. 2a-d) In immunofluorescence study Lupus band was negative again. According to clinicopathologic correlation, miliary pseudolymphoma (lymphocytoma cutis) was proposed.

Immunohistochemistry (IHC) studies with CD3 (pan T cell marker), CD20 (pan B cell marker), Ki67, CD68, $\mathrm{Bcl} 2$ and $\mathrm{Bcl} 6$ staining were made to differentiate between lymphoma and pseudolymphoma. The IHC confirmed polyclonal lymphoid infiltrate: CD20 positive B lymphocytes mostly in germinal centers were surrounded by CD3 positive T lymphocytes mostly in mantle zones of lymphoid follicles. Ki67 staining revealed germinal centers with normal elevated proliferation rates. CD68 was positive in scattered background hitiocytes and follicular dendritic cells. Numerous lymphocytes expressed bcl-6 and scant lymphocytes expressed bcl-2 within germinal centers. So a true cutaneous lymphoma was ruled out. (Fig. 3a-e)

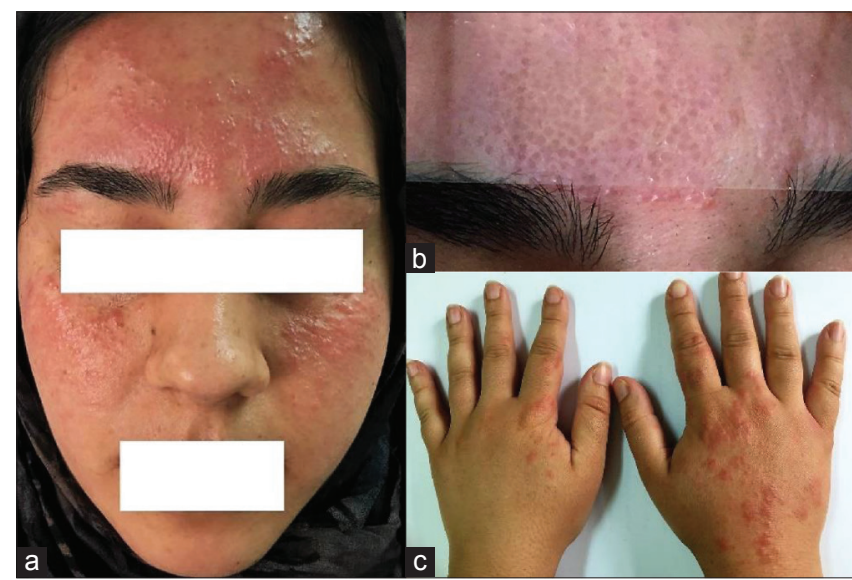

Figure 1: (a) Numerous firm translucent asymptomatic erythematous micropapules are seen on the forehead and cheek regions. (b) Diascopy of the lesions has been shown. (c) Discrete erythematous papules are seen on dorsal aspect of her hands.

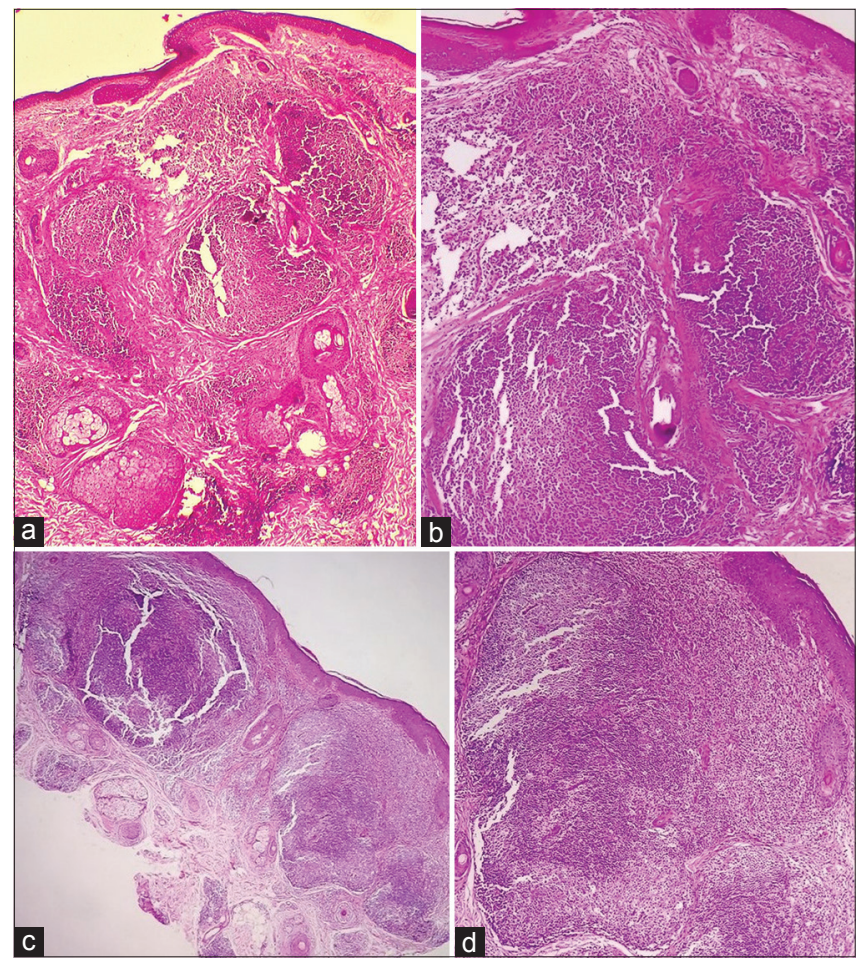

Figure 2: A flattened epidermis with an underlying Grenz zone, dense lymphoid follicle aggregations with ill-defined germinal center in mid and deep dermis [a and $b$ from left cheek, $c$ and $d$ from right cheek]. (a: $\mathrm{H}$ and $\mathrm{E}$, original magnification $\times 4$; b: $\mathrm{H}$ and $\mathrm{E}$, original magnification $\times 10$; : $H$ and $E$, original magnification $\times 10, d$ : $H$ and $E$, original magnification $\times 20$ ).

Blood investigations including complete blood count, erythrocyte sedimentation rate, $\mathrm{C}$ - reactive protein, liver function test, urea, creatinine, calcium, phosphor, antinuclear antibody and angiotensin converting enzyme were within normal levels. Serology for Borrelia Burgdorferi was negative and imaging including chest radiography and abdominopelvic sonography were unremarkable. 


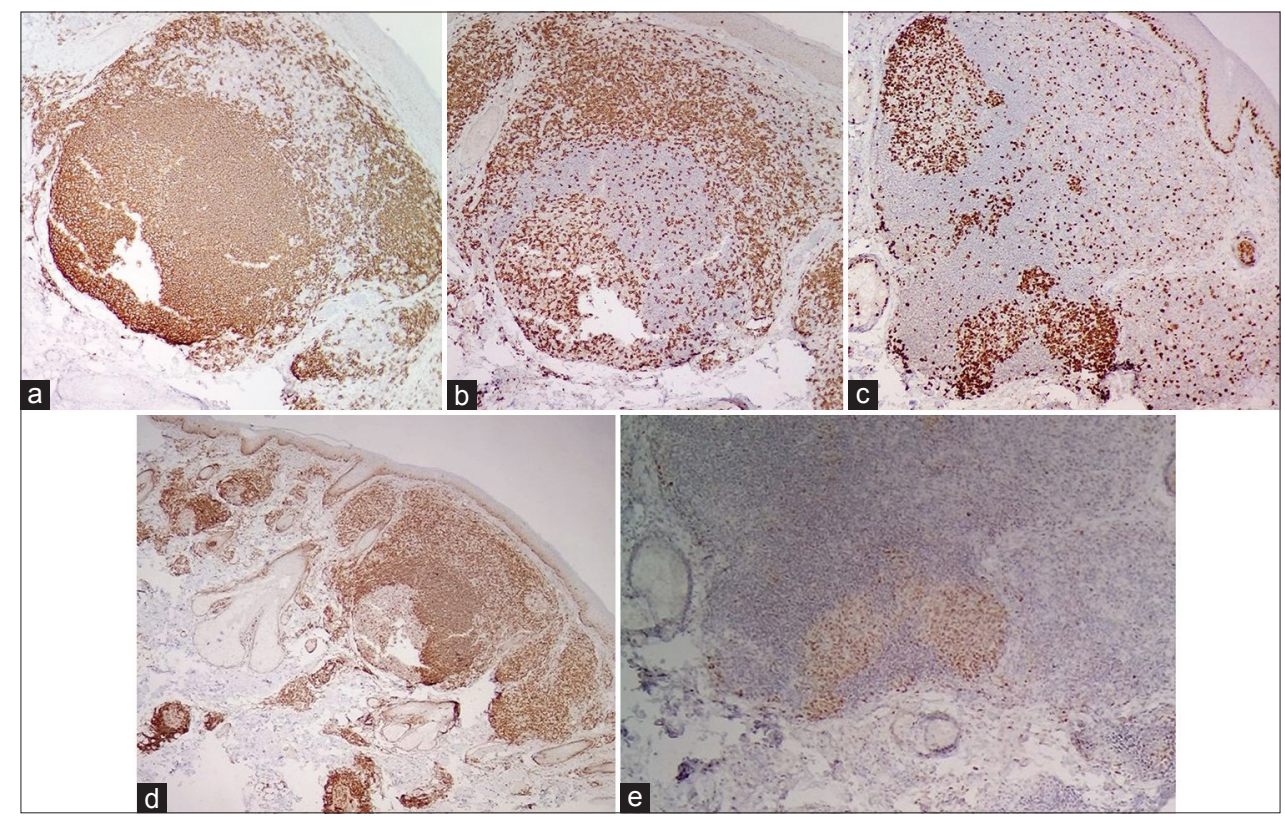

Figure 3: IHC staining results: (a) CD 20 is densely positive in predominant B cell component. (b) CD3 is positive in concurrent T-cell component. (c) In overall Ki67 is positive in 10-15\% of cells, but in about $85 \%$ of germinal center cells. (d) BCL2 is positive in parafollicular component of the infiltration. (e) BCL6 is positive in reactive germinal centers. (a-c and e: original magnification $\times 10$, d: original magnification $\times 4$ ).

Transient photo aggravated papular eruptions on her dorsal hands were diagnosed as polymorphic light eruption (PLE) but our patient would not like to biopsy of these lesions.

We treated her with topical momethasone furoate ointment, hydroxychloroquine tablet $400 \mathrm{mg}$ daily for 6 weeks and sun protection with a good response but she was followed three monthly for any probable recurrence.

\section{DISCUSSION}

Miliarial type pseudolymphoma is a rare type of pseudolymphoma in sun exposed areas with a predominant B cell phenotype [6]. Clinically it has been manifested by multiple translucent asymptomatic pin-head sized papules with a symmetrical distribution mostly over pericenteral areas of the face [3,7-9]. These glistening papules have been resembled as sago grains which have shown opalescence on diascopy [7]. It occurs in children and adult with a female predominance $[1,4,10]$.

Many etiologic factors has been proposed for pseudolymphoma including bites, stings, actinic damage, infections, infestations, drugs; which all of them could be able to produce a foreign antigen $[1,6]$.

Interestingly our patient had photo distributed lesions on the face, also clinically diagnosed transient summer time PLE on her hands which showed that actinic radiation had a role in this regard.

Frain-bell \& Magnus in 1971 and Ferreira \& Silva Duarte in 1997 has been reported association between PLE and disseminated lymphocytoma cutis in their cases $[5,6]$.

On the other hand parasitic infestations such as scabies has been incriminated in pseudolymphoma; our case had no scabies but she had demodex particles in hair infundibulum on the initial biopsy which was misdiagnosed as granulomatous rosacea. Demodex could be able to produce perifollicular inflammation and immune system dysregulation which would be aggravated by sun exposure [11]. We are not sure if this mite could have a role in inducing a miliary pseudolymphoma such as in rosacea. We did not find any association in this regard in the literatures.

An important differential diagnosis for miliarial type pseudolymphoma is miliary primary cutaneous follicle center lymphoma (PCFL). Miliary PCFL would be presented by acneiform or papular lesions on the head and neck areas and could be an imitator of miliarial type pseudolymphoma [12].

Typical lymphoid follicle formations with germinal centers and mantel zones, top-heavy distribution of infiltration and characteristic IHC findings which 
were seen in our patient have not been reported in true lymphoma even in miliarial PCFL [9]. Also a chronic benign course in our case and a good response to hydroxychloroquine were in contrast with a malignant lymphoma.

There are paradoxical reports about the ability of pseudolymphoma in changing to overt lymphoma. Also association with an underlying malignancy has been reported so prolonged follow- up has been recommended $[1,7]$.

We report our case because this is a rare disease and almost 50 cases have been reported in the world. Clinically this could be mistaken easily with other diagnoses because it is a chronic misleading eruption and in all case reports definite diagnosis has been made on the basis of histopathologic findings [9].

In conclusion we should consider miliarial type pseudolymphoma when we observe multiple chronic asymptomatic translucent papules on the face.

\section{Consent}

The examination of the patient was conducted according to the Declaration of Helsinki principles.

\section{Abbreviations}

CLH: Cutaneous lymphoid hyperplasia

IHC: Immunohistochemistry

PCFL: Primary cutaneous follicle center lymphoma
PLE: Poly morphic light eruption.

\section{REFERENCES}

1. Kutlubay Z, Pehlivan O, Engin B. Cutaneous Pseudolymphomas. J Turk Acad Dermatol. 2012;6:1-7.

2. Oliveira E, Badiale G, Moraes M. Lymphocytoma cutis - Case report. An Bras Dermatol. 2013;88:128-31.

3. Jain A, Majumdar B, Sen D, Sen S, Mishra P, Samanta A. Asymptomatic papules over central and pericentral areas of the face. Indian Dermatol Online J. 2015;6:198-200.

4. Goldberg NS, Esterly NB. An extensive papular eruption on the face of a 10-year-old girl. Arch Dermatol. 1986;122:931-2.

5. Ferreira LM, Silva Duarte I. Disseminated lymphocytoma cutis: Case report. Aesth Plast Surg. 1997;21:346-8.

6. Moreno A, Curco N, Serrano T, Garcia J, Llistosella E, Bordas X. Disseminated, miliarial type lymphocytoma cutis. A report of two cases. Acta Dermat Venereol. 1991;71:334-6.

7. Waddington E. Miliary lymphocytoma of the face. Br J Dermatol. 1953;65:217-9.

8. Simpson JR. Miliary lymphocytomata. Proc R Soc Med. 1949;42:135.

9. Moulonguet I, Ghnassia M, Molina T, Fraitag S. Miliarial-type perifollicular B-cell pseudolymphoma (lymphocytoma cutis): a misleading eruption in two women. J Cutan Pathol. 2012;39:1016-21.

10. Nelson LM. Lymphoblastomas in childhood-Cutaneous Manifestations. Calif Med. 1953;78:208-12.

11. Dessinioti C, Antoniou C, Katsambas A. Acneiform eruptions. Clin Dermatol. 2014;32:24-34.

12. Massone C, Fink-Puches R, Laimer M, Rütten A, Vale E, Cerroni L. Miliary and agminated-type primary cutaneous follicle center lymphoma: report of 18 cases. J Am Acad Dermatol. 2011;65:749-55.

Copyright by Gharaei Nejad Kaveh, et al. This is an open-access article distributed under the terms of the Creative Commons Attribution License, which permits unrestricted use, distribution, and reproduction in any medium, provided the original author and source are credited.

Source of Support: Nil, Conflict of Interest: None declared. 